\title{
Phase Two
}

In English Today's first editorial, in January 1985, I wrote that the magazine now existed, with a name, a logo and a shape: 'The first two, we hope, will become well known. As for the third, it is not meant to be fixed and final. It will evolve.'

Since then the name and the logo have become well known, and in small ways the shape has been evolving. In January 1988, the shape will evolve further, in response to feedback from readers, distributors, librarians and other sources. The developments in Phase Two by and large have four aspects: format, durability and convenience, content and 'image', and cost.

Format When planning $E T$, we looked for a size that would distinguish it from conventional scholarly journals. The spacious A4 page size proved convenient for production in the United Kingdom and avoided any impression that English Today would be a junior cousin of Time and Newsweek. It is a size that has proved popular with readers, but one that poses problems elsewhere. Librarians have had difficulty (both literally and psychologically) in finding space for it on their shelves. In addition, although $E T$ looks like a consumer magazine, retailers like W H Smith in Britain have turned it down as 'too intellectual and too infrequent' and American newsstands have found it on the tall side. After much thought, therefore, we are moving to a more compact size which will help librarians without disturbing the retailers who stock $E T$.

Durability and convenience This new-look $E T$ will have 64 pages instead of 44 , will have a spine and a tougher cover, and will travel more securely as a postal package. When a single copy goes into a library, a department or a company, it will sit better on shelves, will more successfully withstand the assault of many hands, and will bế easier to carry around.

Content and 'image' Our correspondence columns are a witness to the interest that $E T$ generates, but we need more openings to the thousands of potential readers who in many places have not yet seen or even heard of our pioneering magazine-cum-journal. For many academics, $E T$ is a 'magazine', relaxed in form while rigorous in dealing with scholarly matters; for many non-academics, it is a 'journal' that opens up avenues to issues that do not always percolate out of college and publishing house. We intend our new format to reflect this unique blend, so that both institutions and advertisers can appreciate the services provided and the importance of our dispersed but influential readership.

Cost Payment in different currencies poses problems, and in some countries payment for a foreign publication is not at all easy. In addition, a specialist periodical like $E T$ may seem expensive, when compared with a consumer magazine with high advertising content. We are constantly trying to find the best approach to such problems, some of which are close to insoluble. However, in 1988 we are adopting a more flexible response:

- a rate for libraries, comparable to conventional journals

- a standard rate for regular subscribers
- a discount rate for students and the retired

- negotiated rates for professional and other associations, for bulk subscriptions

Details of these new arrangements are provided on p. 44.

Apart from these developments, $E T$ will continue (as regards content, contributors and internal design) to provide the kind of variety and depth that we have aimed at from the start. In ET12, David Crystal starts off with the vexed question of the size of vocabulary available to users of English, while Sidney Greenbaum discusses the ways in which grammar needs to be described in the later 20 th century. William Lutz takes a well-documented look at doublespeak, Bent Preisler reports on research into women's and men's uses of the language, John Dougill describes 'Atmosphere English' in Japan, and I review Roget's Thesaurus, a new edition of which has been edited by Elizabeth Kirkpatrick and published by Longman. Our interview this issue is with Maureen Stack, editor of $B B C$ English magazine, and supporting features range over TEIL and IBM, geriatric consultancies on anachronisms, triple negation in Glesca English, a 'joco-serious' work on dialects and creoles, and a variety of other linguistic flora and fauna. Like the remarkable Roget, $E T$ is also a treasure house (see p. 36).

Tom McArthur

The editorial policy of English Today is to provide a focus or forum for all sorts of news and opinion from around the world. The points of view of individual writers are as a consequence their own, and do not reflect the opinion of the editorial board. In addition, wherever feasible, ET leaves unchanged the orthography (normally British or American) and the usage of individual contributors, although the editorial style of the magazine itself is that of Cambridge University Press.

\section{A Call for Papers}

In $E T$ 's files we have cuttings/clippings from a wide range of British and North American newspapers, and a scattering of material from many other sources. If readers would care to add to our files by sending in occasional (titled and dated) material from their local newspapers, etc., or even the odd complete sample of a specially interesting periodical, this would be a great help in widening the range of usage which we can quote in From Our Files.

Letters to the editor should be addressed to a branch of Cambridge University Press (for forwarding), or directly to:

Dr Tom McArthur Editor, English Today

22-23 Ventress Farm Court

Cherry Hinton Road

CAMBRIDGE CB1 4HD

England 